\title{
A ATUAÇÃO DA CRUZ E DA ESPADA PARA DESPOTENCIALIZAR AS LUTAS FEMINISTAS E NATURALIZAR AS FUNÇÕES SOCIAIS DAS MULHERES NAS DÉCADAS DE 1920 E 1930, POR MEIO DAS REVISTAS: O CENTURIÃO E A ORDEM
} AND TO NATURALIZE THE SOCIAL FUNCTIONS OF WOMEN IN THE 1920S AND 1930S, TROUGH THE MAGAZINES: THE CENTURION AND THE ORDE

https://orcid.org/0000-0002-0637-9416 Anna Clara Granado A https://orcid.org/0000-0001-8432-5416 Pedro Henrique Lessa Torres ${ }^{\text {B }}$ https://orcid.org/0000-0003-4460-7704 José Antonio Miranda Sepulveda ${ }^{\mathrm{C}}$

${ }^{\text {A }}$ Universidade Federal Fluminense (UFF), Niterói, RJ, Brasil

${ }^{\text {B }}$ Universidade Federal Fluminense (UFF), Niterói, RJ, Brasil

C Universidade Federal Fluminense (UFF), Niterói, RJ, Brasil

Recebido em: 5 maio 2021 | Aceito em: 29 ag. 2021 Correspondência: Anna Clara Granado (annaclara@id.uff.br)

\begin{abstract}
Resumo
O objetivo deste trabalho é analisar a dialética entre o movimento feminista, em especial a Federação Brasileira pelo Progresso Feminino (FBPF), e dois movimentos conservadores nacionais que se desenvolveram na Primeira República: a Reação Católica e a União Católica Militar (UCM). A atuação desses aparelhos hegemônicos conservadores repercutiu no debate educacional e nas relações de trabalho desenvolvidas na escola e, ao mesmo tempo, freou a ampliação das lutas do movimento feminista. Assim, resgatou-se a historicidade do conservadorismo desenvolvido pela Igreja Católica e pelas Forças Armadas, evidenciando o papel opressor desenvolvido por essas instituições e desnaturalizando não somente a condição social da mulher, como também o vínculo entre católicos e militares com o ideal conservador.
\end{abstract}

Palavras-chave: Primeira República; conservadorismo; catolicismo; feminismo.

\begin{abstract}
The aim of this paper is to analyze the dialectic between the feminist movement, especially the Brazilian Federation for Female Progress, and two national conservative movements that developed in the First Republic: The Catholic Reaction and The Catholic Military Union. The performance of these conservative hegemonic devices had repercussions on the educational debate and on the work relations developed at school, and, at the same time, stopped the expansion of the struggles of the feminist movement. Thus, the historicity of Conservatism developed by the Catholic Church and the armed forces was recovered, highlighting the oppressive role developed by these institutions and denaturalizing not only the social condition of women, but also the link between Catholics and the military with the conservative ideal
\end{abstract}

Keywords: First Republic; conservatism; catholicism; feminism. 


\section{Introdução}

As características históricas que marcaram a luta das mulheres por direitos civis foram instituídas a partir de diferentes correlações de força que se organizaram, principalmente, no período da chamada Primeira República (1889-1930). É objetivo deste artigo analisar o papel de duas forças conservadoras que atuaram contra uma maior participação feminina na sociedade e contra a ampliação de seus direitos: Igreja Católica e Forças Armadas. A principal novidade deste texto é o estudo com base em uma entidade política formada pela fusão de interesses militares e católicos: a União Católica Militar (UCM). Tal entidade foi pouco explorada na historiografia brasileira, em especial na historiografia da educação brasileira. Com isso, pretendemos difundir novas possibilidades de interpretação sobre as disputas em torno dos direitos femininos no Brasil e quais eram os seus principais adversários.

Fizemos uso de uma pesquisa documental tendo como principais fontes os periódicos $O$ Centurião (1928-1929) - produzido pela UCM - e A Ordem (1929-1976) - produzido pela imprensa católica ligada ao Centro Dom Vital, criado por intelectuais católicos em 1921, no movimento conhecido como reação católica, liderado pelo Cardeal Leme, arcebispo do Rio de Janeiro, e pelo intelectual conservador Jackson de Figueiredo.

Com isso, dividimos o texto em três partes, a primeira dedicada ao movimento feminista no Brasil, com foco nos interesses específicos da Federação Brasileira pelo Progresso Feminino (FBPF). A segunda parte do texto foi dedicada à visão dos católicos militares sobre as mulheres, tendo como fontes o Centro Dom Vital e a UCM. Na última parte, à guisa de conclusão, discutimos as tensões entre feminismo e reacionarismo católico.

\section{O movimento feminista na Primeira República}

O movimento feminista brasileiro surgiu com um objetivo principal: conquistar o sufrágio feminino. Contudo, mais do que isso, as pioneiras do movimento lutaram também por uma educação justa e de qualidade para as mulheres, por perceberem que, por meio dela, conseguiriam alcançar outros patamares sociais, uma vez que a sociedade republicana considerava a educação como base para a prosperidade, a moralidade, a saúde, a ordem social e o poder internacional (BESSE, 1999).

Durante o século XIX, o Brasil carregava uma tradição misógina que se baseava no mito da domesticidade. Margareth Rago (2008) nos conta que, nesse período, surgiram teorias para justificar um rebaixamento social da condição feminina, como o mito da inferioridade 
biológica, que propagava a exclusão das mulheres de certos espaços sociais. Essas teorias também buscavam se vincular às afirmativas de que as mulheres eram consideradas como o sexo frágil ou que existiam em caráter complementar aos homens, de modo a angariar argumentos de que elas não poderiam exercer nenhuma outra atividade senão as de guardiãs do lar ou da família, impedindo-lhes o exercício de qualquer atividade que lhes fosse rentável, sendo relegadas ao desempenho de um papel de submissão e de dependência econômica e financeira para com a parte masculina de sua família, ou seja, pai ou marido.

Dessa forma, as mulheres republicanas encontravam mais dificuldades de acesso à escola do que os homens e apenas lhes era permitido alcançar um conhecimento mínimo, voltado, principalmente, para as prendas domésticas. Algumas das estudantes chegavam a cursar o chamado ensino normal, uma modalidade então destinada à profissionalização para magistério, este visto como uma profissão digna para a mulher, por lhe conferir tempo para se dedicar ao trabalho, mas sem abdicar de se ocupar, com prioridade, da sua família. Ademais, segundo Guacira Lopes Louro (1997, p. 444), as mulheres que se dedicassem à docência precisavam possuir uma moral irretocável.

Na Primeira República, o feminismo brasileiro sempre defendeu a educação de todas as mulheres, inclusive das operárias. O movimento acreditava que as mulheres iriam conquistar novos espaços somente por meio da educação. Segundo Susan Besse (1999), ser feminista, ou carregar para si esse termo no Brasil, no final da década de 1910 até os anos de 1930, era controverso e paradoxal ${ }^{\mathrm{i}}$, pois a definição do termo abrangia desde as feministas católicas até mulheres profissionais solteiras que buscavam refúgios nos estudos europeus ou americanos, para demarcarem a sua emancipação feminina. Ressaltamos que esse movimento não era homogêneo e muito menos unilateral: havia uma fragmentação do campo feminista, que abarcava de liberais a anarquistas. Ainda assim, como dito, em muitos grupos as mulheres defendiam a educação feminina como o ponto de caráter de elevação da mulher.

Dentre essas mulheres ditas de classe alta e média, no Brasil, surgiu a FBPF, em 1922, fundada por Bertha Lutz. Essa entidade se desenvolveu de um outro movimento chamado de Liga para a Emancipação Intelectual da Mulher. Ambos os grupos eram tidos como apartidários e compreendidos como grupos de estudos que buscavam o empoderamento do gênero feminino e que discutia, em seus encontros, assuntos tais como: cidadania; educação; ensino público, primário, profissional, superior etc. As principais participantes da Liga para a Emancipação Intelectual da Mulher eram Bertha Lutz e Maria Lacerda de Moura. Ambas acreditavam no poder educacional e que conseguiriam alcançar um grande papel na sociedade brasileira. 
Entretanto, por algumas divergências de opiniões, Maria Lacerda de Moura rompe com a Liga e vai atuar junto ao movimento operário e Bertha Lutz segue caminho com a FBPF, que, em pouco tempo, recebeu a adesão de mulheres de vários estados brasileiros.

A FBPF conseguiu dois efeitos no Brasil: um deles, o principal, foi a conquista, em 1932, do direito ao sufrágio feminino, uma luta que perdurou desde os primórdios da organização; e o outro foi a instituição do Dia das Mães. Vale ressaltar que essa organização não conciliava as preocupações dos diferentes grupos femininos e tinha uma relação muito frágil com as mulheres das camadas mais pobres da sociedade brasileira (BESSE, 1999).

A FBPF, desde sua fundação, organizou uma série de conferências e eventos relacionados aos direitos políticos e sociais das mulheres, todos realizados na cidade do Rio de Janeiro, e que contaram com o apoio de alguns políticos e com uma forte cobertura da imprensa. Ainda segundo Besse (1999), as mulheres da FBPF estavam mais preocupadas com a sua inserção e incorporação na esfera pública, de modo a conquistarem notoriedade em seus meios para, assim, poderem ter efetiva participação política, emprego remunerado, independência econômica e financeira em relação aos homens (pais ou maridos) e provocarem uma transformação na consciência feminina, na sociedade e na cultura brasileira.

De certa forma, as feministas da FBPF desconsideravam as mulheres de fora do seu mundo, visto que as mulheres negras e mais pobres já frequentavam os espaços públicos. Segundo Saffioti (2013), essas mulheres nunca foram alheias ao trabalho, pois estavam sempre à procura de sua sobrevivência e em busca do sustento da sua família. Muitas dessas mulheres já eram inclusive as próprias chefes de suas famílias e viviam em busca de trabalhos temporários e de atividades consideradas malvistas pela sociedade conservadora brasileira, atuando como: artesãs, empregadas domésticas, lavadeiras e operárias de fábricas, entre outros empregos com menos prestígio social. Além disso, a FBPF não batia de frente com as questões morais e éticas impostas pela Igreja, no sentido de discutir e reivindicar pautas com temas que eram tabus da época (alguns assim o permanecem), como divórcio, aborto, maternidade compulsória e amor livre, talvez por medo da repressão que pudesse encontrar dos ditos antifeministas, e buscava flertar com intelectuais e pessoas influentes do período. Em geral, os antifeministas eram considerados um grupo politicamente conservador que combatia a democracia liberal, bem como o feminismo e tudo que pudesse ameaçar o que considerava como as tradições brasileiras.

Os antifeministas não apelavam somente para as emoções do público; procuravam também construir justificações cientificas e morais para o antifeminismo. Afirmavam 
que negar a igualdade política e social às mulheres não implicava na inferioridade das mulheres. (BESSE, 1999, p. 215).

Além dos antifeministas, o movimento feminista brasileiro ficou bastante ameaçado, nos anos de 1920 a 1930, por conta da revitalização do catolicismo como uma força intelectual reacionária, com objetivo de contribuir e popularizar o pensamento católico de direita. Sob a liderança do Cardeal Sebastião Leme, esse movimento buscou criar, na sociedade católica, uma grande antipatia ao feminismo, e fomentou o estabelecimento de grupos organizados como: a Liga Brasileira das Mulheres Católicas, a Aliança Feminista, os Círculos Operários, a Juventude Universitária Católica, a Juventude Operária Católica e a Ação Católica Brasileira ${ }^{\text {ii }}$. Além dos grupos citados, tivemos também, no Brasil, o Centro Dom Vital, instituído, em 1922, por Jackson de Figueiredo, um ideólogo do pensamento católico de direita, que se declarava reacionário e acreditava que a moralidade católica deveria fundamentar toda a atividade humana, principalmente a política nacional, mantinha pensamentos contrários e inflexíveis contra o socialismo, o positivismo e o evolucionismo, alegando serem eles falsos e perigosos e que era necessário conter a anarquia e a revolução, garantindo-se, assim, a preservação da hierarquia e da ordem (BESSE, 1999).

Para além dos antifeministas católicos, também podemos encontrar resistência ao movimento feminista no grupo intitulado de Ação Integralista Brasileira (AIB), liderado por Plínio Salgado e organizado em 1932, o qual julgava que a solução para o problema da mulher seria encontrada apenas na moral religiosa, defendendo o reforço de uma educação religiosa, principalmente voltada para as mulheres.

Na contramão desses grupos, não podemos deixar de citar que o feminismo católico também estava sendo discutido e debatido nos meios de sociabilidade e intelectualidade carioca. Alba Cañizares do Nascimento foi uma das mulheres e intelectuais republicanas que passou a se manifestar por tal tema, alegando que o feminismo católico era o verdadeiro feminismo, com seus argumentos de que a religião não inferiorizava as mulheres em relação aos homens e de que existia nessa relação entre gêneros uma forma de complementaridade, para formação de um par nos laços matrimoniais. Para Alba, a mulher seria responsável pela educação e formação do homem. O feminismo católico teria como fonte de inspiração a Virgem Maria, um modelo ideal a ser seguido, e se comprometia com a defesa de questões como a honra e as virtudes femininas.

Os embates do movimento de mulheres com a sociedade machista e patriarcal da Primeira República foram muito importantes para ampliar a visibilidade do universo feminino 
no Brasil, possibilitando conquistas e garantias de direitos políticos, trabalhistas, sociais e legislativos. Tal movimento acabou culminando na reforma eleitoral de 1932, que deu às mulheres direito ao voto, à licença-maternidade, à amamentação, à instalação de creches no local de trabalho e à licença especial em caso de aborto preventivo ou acidental.

\section{Católicos, católicos militares e a naturalização da função social da mulher}

O objetivo desta seção é dar uma amostra de como católicos e católicos militares reagiram aos movimentos feministas antes retratados. O foco maior será sobre os católicos militares, haja vista que essa categoria foi raramente descrita e analisada na nossa historiografia. Primeiramente, é preciso fazer uma delimitação, para que fique bem claro a qual grupo nos referimos, quando fazemos uso da categoria católico militar, uma vez que essa pode adquirir uma conotação bem ampla. Quando aqui mencionamos os católicos militares, estamos nos referindo aos militares vinculados à UCM. Assim, isso remete a um grupo organizado. Para sermos mais precisos, estamos tratando de uma associação que foi criada, na década de 1920, sob a benção das mais altas hierarquias militares e das mais elevadas autoridades da Igreja Católica. Analisando o contexto do seu surgimento e dos intelectuais católicos que a ela ofereceram o seu apoio, podemos constatar nitidamente a existência de grandes interesses políticos e educacionais por trás dessa associação. Sendo assim, cabem algumas palavras sobre o surgimento da UCM.

Os católicos militares tomaram como ponto de partida da sua associação o ano de 1922. Nesse ano, um grupo de militares teria demonstrado a sua fé, durante a comemoração do centenário da Independência, ocasião em que ofereceram suas armas para que fossem benzidas. Outro marco delimitador é o ano de 1924, quando o esforço de mobilização dos católicos militares teria resultado numa grande comemoração de um evento intitulado Páscoa Militar. A esse evento teriam comparecido cerca de 3 mil homens do Exército, Marinha, Polícia Militar e Bombeiros. Em 1925, teria surgido o primeiro núcleo da associação. Nos anos posteriores, esses núcleos se multiplicaram e espalharam-se por todo o país. Acerca dessa narrativa é preciso fazer algumas ponderações. Em primeiro lugar, levando em consideração o reportado acerca do ano de 1924, podemos notar o caráter amplo da associação, que visava congregar militares de todas as forças, desde Bombeiros e Polícia Militar ao Exército e à Marinha. Em segundo lugar, podemos constatar que essa narrativa possui um caráter ainda não politizante, no sentido de que omite todo o contexto político-institucional que deu origem à UCM (Autor, 2019). 
Para conhecermos a UCM em seu âmago foi preciso analisar minuciosamente fontes até então inéditas na historiografia nacional, como O Centurião (1928-1929) e O Bom Soldado, ambos periódicos produzidos pela associação católico-militar. E isso não foi tudo: também foi necessário confrontar os dados fornecidos por esses periódicos com as obras de alguns intelectuais católicos, para que fosse possível compreender as finalidades políticas que regeram a criação da UCM (Autor, 2019). As matérias contidas em $O$ Bom Soldado, assim como as informações prestadas por $O$ Centurião (1928-1929) não fazem alusão, por exemplo, ao movimento tenentista, nem à campanha presidencial de 1922, e esses dois eventos foram primordiais para o surgimento da associação, merecendo alguns esclarecimentos da nossa parte.

A campanha presidencial de 1922, junto com a de 1910 e 1930, foram as únicas realmente competitivas em toda a Primeira República. Todas as demais foram referendos de uma espécie de consenso oligárquico que se sustentava no pacto entre São Paulo e Minas Gerais, consoante a política dos governadores implementada a partir do governo Campos Sales, e no voto de cabresto, uma vez que o voto secreto somente foi implementado na Era Vargas. Dessas três campanhas, a chapa oposicionista de 1922 foi a que conseguiu o maior percentual de votos, entre aspirantes que não representavam a chapa de situação (PIRES, 1995). Nessa campanha defrontaram-se Arthur Bernardes, candidato oriundo de Minas Gerais e apoiado pelo governo federal, e Nilo Peçanha, candidato oriundo do Rio de Janeiro e apoiado por quatro estados (Rio Grande do Sul, Bahia, Pernambuco e Rio de Janeiro). De acordo com Ferreira (1990), a campanha de 1922 simbolizou a tentativa de formação de um eixo alternativo de poder por parte das oligarquias de estados dissidentes, em busca de maior autonomia e poder no governo central. Enquanto que, para Prestes (1994), a campanha de 1922 foi o berço do movimento tenentista. Acerca dessa última assertiva, é necessário que façamos alguns esclarecimentos no que diz respeito à imprensa e ao episódio das cartas falsas.

A imprensa teve intensa participação na campanha presidencial de 1922, com destaque especial para o Correio da Manhã (1901-1974). Esse periódico estava entre os maiores da capital do Brasil na Primeira República, graças ao seu apelo popular e linguagem agressiva (SODRÉ, 1983). No contexto eleitoral de 1922, ganhou relevo a publicação de duas cartas no jornal. Essas cartas foram atribuídas ao candidato governista Arthur Bernardes e o seu teor era altamente ofensivo aos militares. A primeira carta foi publicada pelo Correio da Manhã no dia 9 de outubro de 1921:

Am. Raul Soares

Estou informado do ridículo e acintoso banquete pelo Hermes, esse sargentão sem compostura, aos seus apaniguados, e de tudo que nessa orgia se passou. Espero que 
use com toda energia de acordo com as minhas últimas instruções, pois essa canalha precisa de uma reprimenda para entrar na disciplina.

Veja se Epitácio mostra agora a sua apregoada energia punindo severamente esses ousados, prendendo os que saíram da disciplina, e removendo para bem longe esses anarquizadores.

Se Epitácio, com medo, não atender, use de diplomacia, que depois do meu reconhecimento, ajustaremos contas. A situação não admite contemporizações, os que forem venais que é quase a totalidade, compre-os com todos os bordados e galões. (BERNARDES, 1921a).

A segunda carta foi publicada no dia 13 de outubro de 1921:

\begin{abstract}
Meu caro Raul Soares
Saudações afetuosas

Ciente dos dizeres da última carta, fico inteirado dos compromissos tomados para o resultado seguro da Convenção. Todavia desacordo com outra prorrogação porque ela devia ter sido realizada antes da chegada do Nilo, pois, como você disse, esse moleque é capaz de tudo.

Remova todas as dificuldades como bem entender, não olhando as despesas, o que já fiz ver ao João Luiz. Das classes armadas nada devemos temer devido aos compromissos assumidos pelo Epitácio agindo com toda a energia.

Da política mineira só tenho [a] adiantar que os elementos do Salles estão sendo trabalhados tenazmente para abandoná-lo e que a sua candidatura a presidência está garantida, porque obrigaremos os políticos recalcitrantes, sob pena de perderem as suas posições, e você, quando me suceder, continuará a levar na devida verba o que falta das grandes despesas que estamos fazendo, para que depois não venha se dar escando. (BERNARDES, 1921b).
\end{abstract}

Essa situação ficou conhecida, pela historiografia, como o episódio das cartas falsas. Mas esse codinome não deve nos enganar. Para muitos militares, aquelas cartas eram verdadeiras. O Correio da Manhã (1901-1974) fez intensa campanha para defender a veracidade dessas cartas, chamando especialistas em grafia até do exterior. Chegou ao ponto de manter as portas da redação abertas para receber oficiais do Exército que quisessem comparar as referidas cartas com outros escritos públicos de Arthur Bernardes (Autor, 2010). A questão das cartas vinculou muitos militares à candidatura de Nilo Peçanha, colocando o país sob a ameaça de golpe militar, o que acabou sendo o ponto de partida para o movimento tenentistaiii.

Em razão de documentos tomados como falsos com base na perspectiva jurídica da época, durante o quadriênio 1922-1926 o governo federal sentiu-se legitimado para censurar e perseguir vários órgãos de imprensa, além do Correio da Manhã (1901-1974), o que deveria nos fazer refletir acerca dos cuidados a serem tomados quando se trata da relação entre notícias falsas e responsabilidade de imprensa. Outra reflexão que podemos extrair, desse caso, é sobre as possíveis consequências das tentativas de envolver as Forças Armadas na política. De acordo com as relações de força vigentes à época, fragmentou-se o Exército, o país entrou em guerra civil e as forças conservadoras, como a Igreja Católica, tiveram um crescimento significativo em influência, não somente na sociedade civil, mas também no aparelho estatal, em especial nas Forças Armadas. 
A ameaça de golpe militar mais a candidatura de Nilo Peçanha - um maçom que, durante o exercício da presidência, em 1909-1910, tentou vetar a entrada de padres jesuítas refugiados de Portugal - criaram o contexto perfeito para o engajamento de conservadores católicos na campanha presidencial. Os conservadores católicos brasileiros, com destaque para Jackson de Figueiredo, influenciados por autores contrarrevolucionários dos séculos XVIII e XIX como Edmund Burke e Joseph de Maistre, enxergavam a ameaça dos valores da Revolução Francesa em vários setores da sociedade. Assim sendo, para o catolicismo conservador, a campanha de 1922 passou a representar a chegada da revolução ao Brasil. Era uma ameaça liberal, mas também comunista. $\mathrm{O}$ fantasma da Revolução Francesa estava associado ao fantasma da Rússia comunista (FIGUEIREDO, 1922).

Dessa forma, Arthur Bernardes contou com grande apoio católico. Os católicos militares passaram a ter a sua organização e o seu crescimento, apoiados pelo governo e por altas patentes militares. Isso porque se entendia que o catolicismo seria um meio de restaurar a disciplina militar quebrada pelo nascente movimento tenentista. A Igreja Católica, inconformada com o fim da assistência religiosa aos militares, decretada no início da Primeira República, e ansiosa por mais prestígio e influência social, também deu forte apoio para o surgimento e fortalecimento de uma associação católico-militar (Autor, 2019).

Assim, tivemos, no início da UCM, a soma de uma conjunção de interesses da Igreja, do Exército e do governo federal. Quando nos referimos a essas instituições, não queremos dizer que havia unanimidade de posições entre elas, afinal, não se deve alimentar o mito da unidade civil-militar- religiosa. No próprio Exército houve oposições à UCM por parte daqueles que entendiam que o catolicismo poderia atrapalhar o desenvolvimento da ciência e da modernização militar. Essas oposições, entretanto, não impediram o crescimento da associação, existente até os dias de hoje.

O caráter da associação nas décadas de 1920 e 1930 era extremamente conservador, associado à extrema direita, de maneira que importantes integralistas estiveram entre os seus quadros e rede de apoio, como Gustavo Barroso e Coronel Francisco Pinheiro. A UCM, por intermédio de um projeto educativo nacionalista e religioso, buscou realizar diversas operações simbólicas cujos intuitos eram reforçar a disciplina militar num momento de intensa divisão interna. Acerca desse vasto projeto, queremos focar o papel daquela associação na naturalização de uma função social subalterna legada às mulheres no contexto das décadas de 1920 e 1930 .

Para tal, antes devemos fazer algumas considerações acerca do conceito de instituição total (GOFFMAN, 2003). Nessas instituições opera-se um segregamento do indivíduo de 
maneira a afastá-lo dos seus demais papéis sociais. Sua liberdade e sua autonomia são restringidas e passa-se a elaborar uma nova subjetividade para esse indivíduo. O seu antigo eu é, em alguma medida, mortificado mediante um sistema complexo de bonificações e repressão. Nesses tipos de instituição, como manicômios, prisões, conventos e quartéis, as pessoas são levadas a passar muito tempo aprisionadas, de maneira que pequenos prêmios e distrações acabam adquirindo muito valor. Assim, pequenas cerimônias, circulação de jornais da instituição e demais atividades passam a ter bastante centralidade. É nesse contexto que devemos enxergar $O$ Centurião (1928-1929), periódico de divulgação da UCM, assim como a própria UCM. Afinal, se por parte das hierarquias militares superiores havia um objetivo disciplinador, para muitos militares a associação católico-militar desempenhava um papel de válvula de escape da rotina militar.

Foi em $O$ Centurião (1928-1929) que se publicaram alguns discursos que revelavam a visão de mundo conservadora católica acerca da família e das relações de gênero, que se propagava com mais intensidade no meio militar do que nos jornais de grande circulação. Mais especificamente, pode-se observar que os objetivos da UCM também englobavam as famílias militares. Nesse sentido é que, no regulamento da UCM em vigor na década de 1930, pregavase que deveria ser ensinado o catecismo aos filhos dos militares. $\mathrm{O}$ mesmo vale para as mais diversas preocupações expressas com relação ao fenômeno educacional e à possibilidade de a juventude ser desorientada por "maus" professores e intelectuais.

No que toca especialmente à questão de gênero, chama atenção um fragmento no qual, em $O$ Centurião, se demonstrou claramente qual era a posição do periódico em relação ao feminismo e ao papel da mulher na sociedade:

O Papa e o feminismo

Numa solenidade que há pouco se realizou no vaticano, para a leitura dos decretos que proclamam a virtude em grau heroico da venerável Paula Frassineti, genovesa da ordem das irmãs Dorotheas, o Papa depois de glorificar a venerável Paula, censurou acremente as mulheres do seguinte modo:

"O sexo feminino tem, em Paula Frassinetti o espelho de todas as virtudes, que deveria ter sempre presente como exemplo digno de imitação. A mulher de hoje oferece argumento a considerações penosas.

É para nós causa de dor imensa vê-la chegar ao esquecimento consciente dos dons que lhe foram confiados: o recato e o pudor. Parece empenhar-se com afinco, para conseguir destruir todo o bem que nela é característico do sexo, e põe um estudo especial em desviar-se da linha que Deus lhe traçou.

E o Santo Padre pergunta: "a que aspira chegar a mulher da época presente? Que quer este feminismo moderno? Para alcançar o que nunca chegará a atingir, perde tudo o que poderia ter legitimamente."

O Pontífice mostra-se sentidíssimo e diz que a sua dor é profunda, porque não somente as mulheres que vivem na mundanidade, mas aquelas que vivem mais recolhidas, e se mostram católicas fiéis, se sentem atraídas pela vaidade, que obscurece, nas suas almas, todas as luzes do bem e desvia os seus retos espíritos que deveriam manter-se 
imaculados. Por isso o exemplo, que deu Paula Frassinetti deve ser posto em relevante destaque.

Ela foi uma mulher animada por um glorioso feminismo, desse feminismo verdadeiro que quer ficar nas suas funções dignas e puras, para o bem do próximo, para a felicidade do lar, o consolo dos pais, a santa guia dos filhos, a dignificação da pátria e a glória da Igreja católica. (O PAPA, 1928, p. 22).

Pode-se observar, pelo trecho citado, que a UCM endossava uma naturalização das funções sociais ocupadas pelas mulheres naquele período, isto é, funções subalternas, restritas às preocupações domésticas e à caridade. Por meio de um capcioso jogo de palavras, a matéria promove uma divisão entre o que seria o feminismo verdadeiro e o feminismo moderno, na qual o primeiro é retratado positivamente, apesar de manter as mulheres nas funções tradicionais de então (O PAPA, 1928). Tal visão foi propagada nos meios católicos militares de maneira a potencializar, no campo militar, uma visão conservadora acerca da mulher. Ademais, essa visão não ficava restrita ao campo militar, porque chegava também às famílias dos militares, se disseminando no corpo social.

As esposas dos militares constavam estatutariamente em uma categoria específica de membras da UCM, deixando claro seu papel subalternizado e complementar ao homem, seguindo assim as orientações e argumentações defendidas pelo próprio Papa. Tratavam-se essas mulheres de: “Art. 16 - Benfeitoras, senhoras e senhorinhas de famílias militares que colaborarem com os associados nas obras de caridade, aos doentes, presos e asilados e famílias de camaradas pobres, catequese e outras obras pias" (ESTATUTO, 1928, p. 11).

Por outro lado, nos eventos da UCM, como a Páscoa dos militares, suas missas e obras de caridade, disseminava-se pelas famílias de militares uma visão de mundo conservadora, que naturalizava a função social da mulher. Essa visão de mundo, difundida nos meios militares, encontrava correspondência com o propagado nos meios conservadores católicos nas décadas de 1920, de 1930 e em parte da de 1940 pelo movimento da reação católica.

Pesquisando o verbete feminismo na revista A Ordem (1929-1976) ${ }^{\text {iv }}$, cujas edições encontram-se disponíveis para consulta na hemeroteca da Biblioteca Nacional, podemos constatar a reprodução da dicotomia entre feminismo verdadeiro e feminismo falso, assim como a insistência na ideia de que o movimento feminista era uma ameaça cujas consequências sociais poderiam se revelar nefastas. Entre as próprias mulheres intelectuais, havia as que defendiam, como Alba Cañizares do Nascimento (1931), o feminismo católico como o verdadeiro feminismo ${ }^{\mathrm{v}}$. Nascimento (1931) se dizia intransigente em relação à honra, às virtudes e à indissolubilidade do casamento, afirmando ser a família a base de toda uma sociedade. Nesse verdadeiro feminismo, era pregada a indissolubilidade do casamento, pois, 
caso fosse concedida a permissão de separação dos casais, iria correr um grande risco de propagação da imoralidade, da poligamia e da falta de estabilidade moral familiar. Para Nascimento (1931), a religião, a Igreja e o cristianismo eram peças fundamentais para as mulheres poderem imperar nos seus lares, na política, na religião e em todos os domínios da vida social.

Chama atenção um texto de Tristão de Athayde (1941), intitulado Feminismo. Tristão de Athayde (1941), sucessor de Jackson de Figueiredo na liderança da revista A Ordem (19291976) e maior liderança leiga católica por muitas décadas, apresentou uma visão do movimento feminista como uma proposta de degeneração do papel da mulher ocupado tradicionalmente na sociedade cristã. O feminismo, em sua visão, seria uma consequência do individualismo e do socialismo (ATHAYDE, 1941).

O pensamento de Tristão de Athayde, codinome de Alceu Amoroso Lima, passaria por muitas transformações no pós-Segunda Guerra Mundial. Mas o seu texto de 1941 é bastante representativo das ideias defendidas ao longo de 1920 e 1930 pelo catolicismo ultramontano (ATHAYDE, 1941). Ideias que, por meio da UCM, se propagaram no meio militar, ganhando ainda mais difusão social e dificultando o processo de emancipação proposto pelos movimentos feministas. Vale destacar que o ímpeto conservador não foi suficiente para estancar ou imobilizar o avanço das conquistas femininas. Muito se sabe, hoje, sobre a história de mulheres ${ }^{\mathrm{vi}}$ que enfrentaram a luta por direitos. Nesse contexto, vale destacar a importância da educação.

\section{A educação em questão: considerações finais}

Para encerrarmos este artigo, não poderíamos deixar de tecer uma reflexão sobre a centralidade que a questão educacional tomou no debate público dos anos 1920 e 1930. Tal centralidade envolvia também a discussão do papel feminino, nesse processo. A FBPF produziu uma agenda que envolvia a formação profissional das mulheres. Para isso, a educação era fundamental. A entidade era representativa de burguesas e seus interesses de elite, que, com efeito, reverberavam nas demais frações de classe da sociedade brasileira, no período. Dessa forma, o controle sobre a educação envolvia também um importante debate de gênero. Em contrapartida, a reação conservadora católica e militar funcionava como um freio importante para a ampliação das lutas feministas. Na pauta social, temas como o divórcio, por exemplo, foram substituídos por temas referentes à formação/educação, até mesmo porque esse era um assunto de destaque, que envolvia a própria sobrevivência das mulheres no mundo do trabalho. 
A discussão educacional, portanto, nessas décadas em destaque no artigo (1920-1930), voltou à ordem do dia, antes praticamente invisibilizada desde a Proclamação da República. Tanto que as reformas educacionais posteriores àquelas feitas por Benjamim Constant no início da república foram decretadas pelo Poder Executivo “[...] com base em autorizações do Congresso constantes de emendas às leis orçamentárias: como disse Felix Pacheco, a legislação educacional se fazia na "cauda dos orçamentos"” (CUNHA, 2007, p. 137). O surgimento de associações como a Associação Brasileira de Educadores (ABE), a Associação de Escolas Católicas (AEC) e outras confirmou a renovação da importância da educação, o que significou um incremento do debate educacional na sociedade, mesmo que boa parte das propostas veiculadas não partissem de educadores - tampouco os membros dessas associações eram, de fato, da área da educação.

Nesse contexto, a FBPF ajudou a dar visibilidade ao debate educacional trazendo à tona uma demanda reprimida de mulheres que queriam mais espaço na sociedade brasileira. E não só no mundo do trabalho, mas também no mundo político, científico... Na contramão, a luta do movimento reacionário católico e militar, em especial da UCM, girava em torno de essencializar a mulher. Defender que algumas atividades eram naturalmente femininas e que poderiam, pois, ser atribuídas às mulheres equivalia a liberar somente a potencialidade daquilo que se propunha como parte da natureza feminina, em uma resposta ao inevitável crescimento da participação das mulheres no mercado de trabalho, em especial na educação, não só como professoras, mas como inspetoras, secretárias e até diretoras de escolas. Entretanto, tal movimento de naturalização que buscou invisibilizar, por um lado, as lutas das mulheres, por outro significou, também, uma vitória do movimento feminista no que tocava ao livre acesso das mulheres ao trabalho escolar.

$\mathrm{Na}$ abertura deste texto mencionamos que o movimento feminista surgiu com uma pauta principal: conquistar o sufrágio feminino. Mas, também afirmamos a centralidade da educação como meio de se atingir prosperidade, saúde e poder. Os reacionários católicos, endossados pela UCM, se apropriaram da palavra feminismo para nela tentar contemplar seus valores conservadores, transmitindo ideais que se firmavam no sentido oposto da educação emancipadora defendida por muitas militantes feministas. Usaram a palavra feminismo para defender que a mulher se mantivesse numa posição subalterna e exclusivamente doméstica. Essa palavra foi alvo e permanece até hoje em um campo de disputa. Fiquemos alertas, pois essa luta não está nem perto de acabar. 


\section{Referências}

A ORDEM. Rio de Janeiro: Centro Dom Vital, 1929-1976.

ATHAYDE, Tristão de. Feminismo. A Ordem, Rio de Janeiro, p. 569, dez. 1941.

BERNARDES, A. [Am. Raul Soares]. Correio da Manhã, Rio de Janeiro, 9 out. 1921a. . [Meu caro Raul Soares]. Correio da Manhã, Rio de Janeiro, 13 out. 1921b.

BESSE, S. Modernizando a desigualdade: reestruturação da ideologia de gênero no Brasil 1914-1940. São Paulo: Editora da Universidade de São Paulo, 1999.

CORREIO DA MANHÃ. Rio de Janeiro, 1901-1974.

CUNHA, Luiz Antônio. A universidade temporã: o ensino superior - da colônia à Era Vargas. São Paulo: Unesp, 2007.

CURY, Carlos Roberto Jamil. Ideologia e educação brasileira: católicos e liberais. São Paulo: Cortez \& Moraes, 1978.

ESTATUTO da União Católica Militar. O Centurião, Rio de Janeiro, n. 7-8, nov./dez. 1928.

FERREIRA, Marieta de Moraes. Conflito regional e crise política: a reação republicana no Rio de Janeiro. $2^{\text {a }}$ ed. Rio de Janeiro: Cpdoc, 1990.

FIGUEIREDO, Jackson. A reação do bom-senso: contra o demagogismo e a anarquia militar. Rio de Janeiro: Edição do Anuário do Brasil, 1922.

GOFFMAN, Erving. Manicômios, prisões e conventos. São Paulo: Editora Perspectiva, 2003.

HORTA, José Silvério Baía. O hino, o sermão e a ordem do dia: a educação no Brasil (19301945). Rio de Janeiro: Ed. UFRJ, 1994.

LOURO, Guacira Lopes. Mulheres na sala de aula. In: PRIORE, Mary del (Org.); BASSANEZI, Carla (Coord.). História das mulheres no Brasil. São Paulo: Contexto; Ed. Unesp, 1997. p. 443-481.

NASCIMENTO, Alba Cañizares do. O verdadeiro feminismo e o feminismo católico. Rio de Janeiro, 25 out. 1931. Texto para conferência realizada no Congresso Paroquial de Campo Grande. Arquivo pessoal da família.

O CENTURIÃO. Rio de Janeiro: União Católica Militar, 1928-1929.

O PAPA e o feminismo. O Centurião, Rio de Janeiro, n. 5-6, set./out. 1928.

PIRES, Aloildo Gomes. Eleições presidenciais na Primeira República: uma abordagem estatística. Salvador: São Judas Tadeu, 1995. 
PRESTES, Anita Leocádia. Os militares e a reação republicana. Rio de Janeiro: Ed. Vozes, 1994.

PRIORE, Mary del (Org.); BASSANEZI, Carla (Coord.). História das mulheres no Brasil. São Paulo: Contexto; Ed. Unesp, 1997.

RAGO, M. Os prazeres da noite: prostituição e códigos da sexualidade feminina em São Paulo (1890-1930). $2^{a}$ ed. São Paulo: Paz e Terra, 2008.

Do cabaré ao lar: a utopia da cidade disciplinar e a resistência anarquista. 4. ed. São Paulo; Rio de Janeiro: Paz e Terra, 2014.

SAFFIOTI, H. A mulher na sociedade de classes: mito e realidade. 3. ed. São Paulo: Expressão Popular, 2013.

SCOTT, J. A cidadã paradoxal: as feministas francesas e os direitos do homem. Florianópolis: Mulheres, 2002.

SODRÉ, Nelson Werneck. História da imprensa no Brasil. $3^{\mathrm{a}}$ ed. São Paulo: Martins Fontes, 1983.

SOIHET, R. História das mulheres. In: CARDOSO, C. F.; VAINFAS, R. (Org.). Novos domínios da história. Rio de Janeiro: Elsevier, 2011.

\footnotetext{
${ }^{i}$ Segundo Joan Scott (2002), o termo paradoxo marca uma posição de enfrentamento à tradição.

ii Vale destacar que esses grupos criados pela Igreja Católica subjugavam as mulheres, defendendo que se as mantivesse sempre em submissão e em exercício de papéis sociais subalternos.

iii $\mathrm{O}$ apoio de extenso segmento das Forças Armadas à candidatura de Nilo Peçanha não foi obtido apenas em função do caso das cartas. Desde o início das movimentações eleitorais houve uma intensa tentativa de envolver os militares na campanha. Os próprios militares já vinham dando sinais de interesse no pleito, em especial o Marechal Hermes da Fonseca. Dessa forma, havia um contexto propício ao seu engajamento, no momento de publicação das cartas. Além disso, também o favoreceu a conturbada relação do governo Epitácio Pessoa com os militares, uma vez que aquele foi o primeiro presidente a nomear um civil para o Ministério da Guerra e negou desejados aumentos do soldo dos militares, o que afetou especialmente as patentes mais baixas, num momento de crise econômica.

iv Sobre a reação católica encabeçada pelo Cardeal Leme e por Jackson de Figueiredo, que criaram o Centro Dom Vital e a revista A Ordem (1929-1976), conferir Cury (1978) e Horta (1994).

${ }^{v}$ Conforme manifesta Nascimento (1931) em uma conferência - cujo texto foi obtido em consulta ao acervo pessoal da educadora - intitulada $O$ verdadeiro feminismo e o feminismo católico.

vi Sobre a história de luta das mulheres ver: Rago (2008, 2014); Saffioti (2013); Soihet (2011) e Priore e Bassanezi (1997).
} 